\title{
The Nexus between Stock Returns of Oil Companies and Oil Price Fluctuations after Heavy Oil Upgrading: Toward Theoretical Progress
}

\author{
Mojtaba Sedighi ${ }^{1,2, *(\mathbb{D})}$, Majid Mohammadi ${ }^{3}$, Saeed Farahani Fard ${ }^{4}$ and Mehdi Sedighi ${ }^{5,6, *}$ \\ 1 Department of Finance, Qom Branch, Islamic Azad University, Qom 3749113191, Iran \\ 2 Young Researchers and Elite Club, Qom Branch, Islamic Azad University, Qom 88447678, Iran \\ 3 Department of Energy Engineering, Faculty of Science, Qom University of Technology, Qom 151937195, Iran \\ 4 Department of Management and Economics, University of Qom, Qom 3716146611, Iran \\ 5 Department of Chemical Engineering, University of Qom, Qom 3716146611, Iran \\ 6 Center of Environmental Research, University of Qom, Qom 3716146611, Iran \\ * Correspondence: sedighi91@alumni.ut.ac.ir (M.S.); sedighi@qom.ac.ir (M.S.)
}

Received: 15 February 2019; Accepted: 5 July 2019; Published: 10 July 2019

check for updates

\begin{abstract}
This study attempts to discover the nexus between crude oil price fluctuation after heavy oil upgrading and stock returns of petroleum companies in the U.S. Stock Exchange for the years 2008 to 2018. One of the methods of upgrading heavy crude oil is to extract asphaltene from crude oil. Considering the Asphaltene Removal (AR) as a factor in the nexus between oil price and the stock market is an innovation in the literature of energy finance. Asphaltenes cause many problems in the petroleum industry, which increases the cost of oil production and reduces the financial efficiency of oil companies. The AR is certainly one of the significant matters of the oil industry and can affect the price of oil. Therefore, changes in the price of oil can influence the price of oil company stocks. Hence, changes in stock prices will certainly affect the stock returns of oil companies. In an effort to solve this puzzle, the four financial models were employed to explore the nexus between oil price fluctuations and stock returns. The analysis of the results demonstrated that the oil price fluctuations caused by the removal of asphaltenes influence the stock returns of petroleum companies. Eventually, the theoretical hypothesis was confirmed by considering the USA as a case study. The outcomes of this investigation are a theoretical progression in areas related to the petroleum industry and the stock market that could lead to the adoption of new investment policies in the petroleum industry including investing in new procedures to manage and decrease the costs and time of the AR process, which would result in the advancement of petroleum companies. In fact, we have introduced a modern investment strategy in the oil industry aimed at reducing oil production costs, improving financial statements and increasing the stock returns of petroleum companies. Eventually, we will present new investment policies in the oil industry that can lead to economic growth and development of financial markets especially stock market, derivatives market, futures exchange, commodities exchange, as well as bond market.
\end{abstract}

Keywords: stock returns; oil price; CAPM; heavy oil upgrading; AR; oil price fluctuations; GARCH

JEL Classification: B26; C10; C58; E30; F37; G10; G20; O16; O21; O30; Q40; Q49

\section{Introduction}

Crude oil is one of the most valuable commodities in the world. Its price affects the financial markets and economic systems at each scale. Crude oil prices are extremely sensitive and fluctuate due to many factors, including supply, demand, derivatives, political events and crises (Kilian 2009). 
Financial specialists believe that the forecasting the path of crude oil prices are extremely challenging since they are unstable and complex and rely on different conditions. They employ a variety of predicting tools to forecast the correct trends of oil price fluctuations (Yu et al. 2008). The AR is a heavy oil Upgrading operation, i.e., the conversion process, which converts primary products into an acceptable raw material for petroleum refineries (Mohammadi et al. 2019b).

Asphaltene, a very heavy fraction of crude oil, precipitation and deposit can occur at different stages during oil production (Safari et al. 2017). These deposits may plug the wellbore tubing and valves, as well as pipeline and industrial equipment. Asphaltene is definitely found in crude oil and must be eliminated during the processing stages of crude oil. Asphaltene problems can considerably decrease well profitability, resulting in problematic operational problems, reducing production and increasing the costs of oil production (Mohammadi et al. 2015).

Many studies have presented the AR methods and asphaltene problems in the petroleum and petrochemical industry. One of the useful methods for removal of asphaltene is to apply chemical additives such as solvents (Chen et al. 2012), surfactants (Kashefi et al. 2016b), polymers (Kashefi et al. 2016a), nanoparticles (Mohammadi et al. 2019a) and adsorbents (Mohammadi et al. 2014).

Regarding the serious operating problems encountered in the presence of asphaltenes, the removal of asphaltenes from crude oil seems to be essential. Separating asphaltenes not only removes the problem of asphaltene precipitation but also improves the crude oil specifications, including increasing API gravity and reducing viscosity that they have a significant impact on the price of crude oil. Hence, the aforementioned issues will lead to variations in oil price (Sedighi et al. 2018a, 2018b).

The fluctuations in the oil price are reflected in the different financial markets, and in particular the stock exchange (Jones and Kaul 1996). Although financial media expect the price of oil to stimulate the stock market, the empirical evidence of the effect of changes in crude oil prices on stock prices is merged. The variations in the price of crude oil are generally regarded as a key element to understanding the fluctuations in stock prices (Kilian and Park 2009).

Fluctuations in the price of oil are an essential and applied issue to research, which in turn may demonstrate the upcoming investments in the financial markets. Developed economies intensely rely on oil consumption for their economies to thrive. Hence, fluctuations in oil prices, for whatever reason, can have serious effects on these economies. Oil price changes have an effect on the production process and the financial efficiency of corporations, which eventually affects their EPS, DPS, income and also stock prices. The rise in oil prices is unlikely to have much impact on the various sectors of the economy, as their dependencies in the oil industry are different. For example, rising oil prices are expected to increase investment in petroleum companies' stocks, which will increase oil production by drilling companies in the coming years (IEA 2018). As a result, the expected increase in oil production could lead to an increase in cash flow and higher financial efficiency of these firms. Although it is generally acknowledged that variations in oil prices have a significant effect on the financial performance of numerous companies, very few empirical studies have been conducted to assess the sensitivity of stock prices of petroleum companies to fluctuations in oil prices after the AR.

Many researchers investigated the nexus between the price of oil and the financial markets especially the stock exchange, but none of them takes into account the AR factor (Faff and Brailsford 1999; Papapetrou 2001; Sadorsky 2001; Cong et al. 2008; Hammoudeh and Li 2008; Miller and Ratti 2009; Arouri and Nguyen 2010; Gogineni 2010; Al-Tamimi et al. 2011; Elyasiani et al. 2011; Jung and Park 2011; Mohanty et al. 2011; Arouri et al. 2012; Arouri and Rault 2012; Broadstock et al. 2012).

The purposes of this article are to add to the rare literature for this novel matter and conceptualization for future researches. In fact, we intend to move towards theoretical advancement in this new matter. The literature on this topic has two main parts. First, four financial models have been applied that were not previously utilized to evaluate the relationship between oil price and stock exchange. Second, the modeling structure was expanded from bivariate to a multivariate one. 
In other words, the bivariate model was improved to a multivariate model by adding a third factor, namely the AR factor. Therefore, the developed models are an improvement over the other studies used in the current literature.

The rest of this paper is structured as follows: In Section 3, we express the notations used in this paper. Section 4 explains the data and methodology. Section 5 proposes the results of this paper. Finally, in Section 6 conclusions and investment policies are presented.

\section{Background}

Despite the prevalent positions in the financial press, there is no general agreement on the nexus between crude oil prices and stock prices amongst financial analysts. For instance, (Kling 1985) inferred that the rise in oil prices is relevant to the stock market decreases. On the other hand, (Chen et al. 1986) indicated that changes in the price of oil have no effect on asset pricing.

(Jones and Kaul 1996) revealed a negative correlation between oil price variations and total stock yields. Nevertheless, (Huang et al. 1996) discovered no negative nexus between stock yields and oil price variations over time, and (Wei 2003) claimed that the decline in U.S. stock prices in 1974 could not be described by oil price rise in 1973.

Many scientific studies have looked at the effect of oil price variations on financial markets, specifically, stock exchange. (Hamilton 1983, 1996) was one of the first to show that oil price fluctuations have a substantial impact on the US financial system.

(Sadorsky 1999) analyzed the nexus between oil prices and stock yields in the USA on the basis of monthly information. His research shows that stock yields decrease in a short time as a reaction to an increase in oil prices.

(El-Sharif et al. 2005) examined the nexus between crude oil prices and equity values in the oil and gas sectors of the UK applying a multi-factor approach utilizing daily information. They realized that an increase in oil prices boosts the yields in the energy markets.

(Nandha and Faff 2008) examined the impact of oil price variations on universal industry indices between 1983 and 2005. They indicated that rising oil price had a negative effect on stock yields of all sections with the exception of exploration and petroleum and gas companies.

(Narayan and Narayan 2010) examined the effect of oil prices on Vietnam's stock prices utilizing daily information from 2000 to 2008. They found that stock prices, oil prices, and nominal exchange rates are coordinated, and oil prices have a positive and considerable effect on stock prices. Their outcomes are incompatible with theoretical expectancies.

(Aloui et al. 2012) examined the impacts of oil price shocks on stock market yields utilizing information from 25 emerging countries. Their research focuses on an analysis of long-run correlation and a conditional multi-factor pricing model. The outcomes demonstrated that oil price risk is considerably priced in emerging markets and that the oil effect is asymmetric with regards to market cycles.

(Cunado and de Gracia 2014) evaluated the effect of oil price shocks on stock returns for twelve oil importing European economies utilizing VAR and VECM from 1973 to 2011. They found that the reaction of the European stock returns to oil price shock could be varied greatly based on the primary causes of the oil price fluctuations. The outcomes indicated that oil price fluctuations have a negative effect on European stock market yields.

(Narayan and Gupta 2015) investigated the role of oil prices in predicting stock returns utilizing monthly time-series historical information from 1859 to 2013. They employed a predictive regression method which considers three main attributes of the information. They found that oil price forecasts US stock returns and both positive and negative oil price variations are key forecasters of US stock returns.

(Zhu et al. 2016) employed a quantile impulse response method to examine the effect of oil price shocks on Chinese stock returns. They found that the responses of the Chinese stock market return to oil price shocks varied significantly, based on the phases of economic growth and whether the shock is 
related to demand or supply. The outcomes of their work prove that the effects of oil price shocks on Chinese stock yields display asymmetric specifications.

(Shaeri and Katircioğlu 2018) evaluated the relationship between oil prices and stock prices of oil, technology and transportation firms under multiple regime shifts. They used weekly data from 1990 to 2015 in the U.S. stock markets. The final outcomes proved that there exist long-term relationships among stock indices, crude oil prices, short-run interest rates and the S\&P 500. Also results demonstrated that stock prices of oil companies are positively influenced by oil prices to a higher level compared to that of technology and transportation stocks.

(Çevik et al. 2018) examined the causal nexuses between price fluctuations in oil markets and international stock yields employing approaches of (Cheung and Ng 1996) and (Hong 2001). They discovered that there is a causal nexus between oil price fluctuations and G7 countries' stock yields for some periods. Additionally, they realized that there might be a distinction between the fluctuations in Brent and WTI oil prices with regards to their Granger-causal impacts on oil-importing emerging markets' stock yields. Their outcomes presented more evidence that the impacts of oil price fluctuations on stock yields might be distinct according to the movements in the stock exchanges. This study is in accordance with the results of (Lee et al. 2012).

(Lee and Baek 2018) employed the nonlinear ARDL method to study the effect of oil price changes on the stock prices of renewable energy firms. They also noted that fluctuations in oil price had asymmetric effects on renewable energy stock prices in the short-term. The outcomes of their research indicated that increasing oil prices led to a rise in the stock prices of renewable energy companies in the short-term but not in the long-term.

(Shaeri and Katircioğlu 2018) evaluated the relationship between oil prices and stock prices of oil, technology and transportation firms under multiple regime shifts. They used weekly data from 1990 to 2015 in the U.S. stock markets. The final outcomes proved that there exist long-term relationships among stock indices, crude oil prices, short-run interest rates and the S\&P 500. Also, results demonstrated that stock prices of oil companies are positively influenced by oil prices to a higher level compared to that of technology and transportation stocks.

According to the analysis of related studies, the outcomes of assessment of the effect of oil price fluctuations on stock returns are complex because of many reasons such as application of diverse methodologies, the time period of the research, the kind of econometric and financial models, the conditions of countries, etc.

After considering previous studies on the nexus between oil price and the stock market, the novelty of our research work is that we consider the AR factor in the nexus between oil price and stock markets.

\section{Notations}

The following notations are employed in the entire article:

$\begin{array}{ll}R_{i t} & \text { The yield of petroleum companies } i \text { in the period } \mathrm{t} \\ P_{i t} & \text { The price index } i \text { in time } \mathrm{t} \\ \gamma_{i} & \text { The stock sensitivity index in presence of changes in petroleum price after the AR } \\ \beta_{i} & \text { The market coefficient } \\ R_{O, t} & \text { The petroleum price changes after the AR } \\ R_{O, t-1} & \text { The lagged petroleum yields } \\ R_{W, t}^{\circ} & \text { The orthogonal yield of the world market } \\ b_{0} & \text { The estimator of } a \\ b_{1} & \text { The estimator of } c \\ A_{M} & \text { The artificial market variable } \\ A_{O} & \text { The artificial oil variable } \\ \gamma_{i}^{A} & \text { The sensitivity index of stock i before petroleum price movements }\end{array}$




\section{Data and Methodology}

This study evaluates the effect of the AR on stock returns of oil companies. According to the findings of the oil industry, the price of crude oil fluctuates positively on the removal of asphaltenes from crude oil. The hypothesis is that after the AR there are positive changes in the stock yields of petroleum companies.

To focus on this issue, 30 petroleum companies were examined and their returns relevant to changes in crude oil prices were measured applying GARCH models, which are best for stock returns. GARCH procedures are extensively used in the modeling of asset returns and inflation in finance and economics due to their advantages and efficiency. GARCH procedures, which are autoregressive, seek to minimize forecasting errors by accounting for errors in previous predictions thereby improving the precision of consecutive forecasts. In this investigation, the standard $\mathrm{GARCH}(1,1)$ was applied (Bollerslev 1986; French et al. 1987; Lamoureux and Lastrapes 1990; Nelson 1990).

The thirty petroleum companies (Listed in Table 1) assessed in this research have been selected from American oil, gas and petrochemical companies for the period of 2008 to 2018, which are admitted in U.S. stock exchange.

We perform four models by applying the daily/monthly/yearly stock returns of the 30 petroleum companies as mentioned. Table 2 indicates the number and time period of observations. All data about oil price, stock price and stock returns have been collected from www.nyse.com, www.nasdaq.com and www.marketwatch.com.

Table 1. Petroleum Companies.

\begin{tabular}{cccc}
\hline Name & Stock Symbol & Name & Stock Symbol \\
\hline ExxonMobil & NYSE: XOM & Southwestern Energy & NYSE: SWN \\
Vaalco Energy & NYSE: EGY & Hess Corporation & NYSE: HES \\
Whiting Petroleum & NYSE: WLL & Range Resources & NYSE: RRC \\
WPX Energy & NYSE: WPX & Linn Energy & NASDAQ: LNGG \\
Rex Energy & NASDAQ: REXX & Pioneer Natural Resources & NYSE: PXD \\
Noble Energy & NYSE: NBL & Murphy Oil & NYSE: MUR \\
Laredo Petroleum & NYSE: LPI & Newfield Exploration & NYSE: NFX \\
Occidental Petroleum & NYSE: OXY & Concho Resources & NYSE: CXO \\
ConocoPhillips & NYSE: COP & Oasis Petroleum & NYSE: OAS \\
Continental Resources & NYSE: CLR & Marathon Oil & NYSE: MRO \\
Denbury Resources & NYSE: DNR & SandRidge Energy & NYSE: SD \\
Devon Energy & NYSE: DVN & SM Energy & NYSE: SM \\
Energen & NYSE: EGN & Chesapeake Energy & NYSE: CHK \\
EOG Resources & NYSE: EOG & Chevron Corporation & NYSE: CVX \\
EQT & NYSE: EQT & Cimarex Energy & NYSE: XEC \\
\hline
\end{tabular}

Table 2. Time periods and observations.

\begin{tabular}{ccc}
\hline \multicolumn{2}{c}{ Time Period } & \multirow{2}{*}{ Observations } \\
\cline { 1 - 2 } From & To & \\
\hline $01 / 01 / 2008$ & $12 / 31 / 2008$ & 372 \\
$01 / 01 / 2009$ & $12 / 31 / 2009$ & 415 \\
$01 / 01 / 2010$ & $12 / 31 / 2010$ & 544 \\
$01 / 01 / 2011$ & $12 / 31 / 2011$ & 658 \\
$01 / 01 / 2012$ & $12 / 31 / 2012$ & 749 \\
$01 / 01 / 2013$ & $12 / 31 / 2013$ & 864 \\
$01 / 31 / 2014$ & $12 / 31 / 2014$ & 983 \\
$01 / 01 / 2015$ & $12 / 31 / 2015$ & 1172 \\
$01 / 01 / 2016$ & $12 / 31 / 2016$ & 1246 \\
$01 / 01 / 2017$ & $12 / 31 / 2017$ & 1342 \\
$01 / 01 / 2018$ & $12 / 31 / 2018$ & 1460 \\
\hline
\end{tabular}


To achieve reliable outcomes, only the AR factor was considered and the inflation impact and other factors such as supply, demand, political events, etc. were removed because removing the impacts of inflation and other factors on the stock returns allows the financial managers and investors to observe the accurate influence of the AR factor without external factors.

All of the price scopes were turned into profitability scopes with respect to the Equation (1):

$$
R_{i t}=\log \left(\frac{P_{i t}}{P_{i t-1}}\right)
$$

After the AR and based on crude oil prices during the years 2008-2018, the crude oil price after the AR was simulated by considering the evidence and statistics in the petroleum industry to examine the hypothesis. To calculate the crude oil hypothetical price after the AR, yearly report and financial data of Halliburton Company have been applied (Halliburton 2018). Asphaltene sediments can cause widespread and costly mechanical problems in the petroleum industry. Halliburton provides various services which can contribute to the removal of these deposits (Halliburton 2018). We also used the information of "DWAX" and "ParaSolve Canada Inc." which are the Canadian oil field service companies, specializing in the removal of paraffin and asphaltene restrictions from producing oil wells and flow lines while the well remains operational (DWAX 2018; Para Solve Canada 2018).

Figure 1 shows the daily closing price of the WTI crude oil over the last ten years. Prices are quoted in US dollars (Crude Oil Prices). Historical prices of crude oil over the last ten years provided in Table 3. All prices are in U.S. dollars (\$).

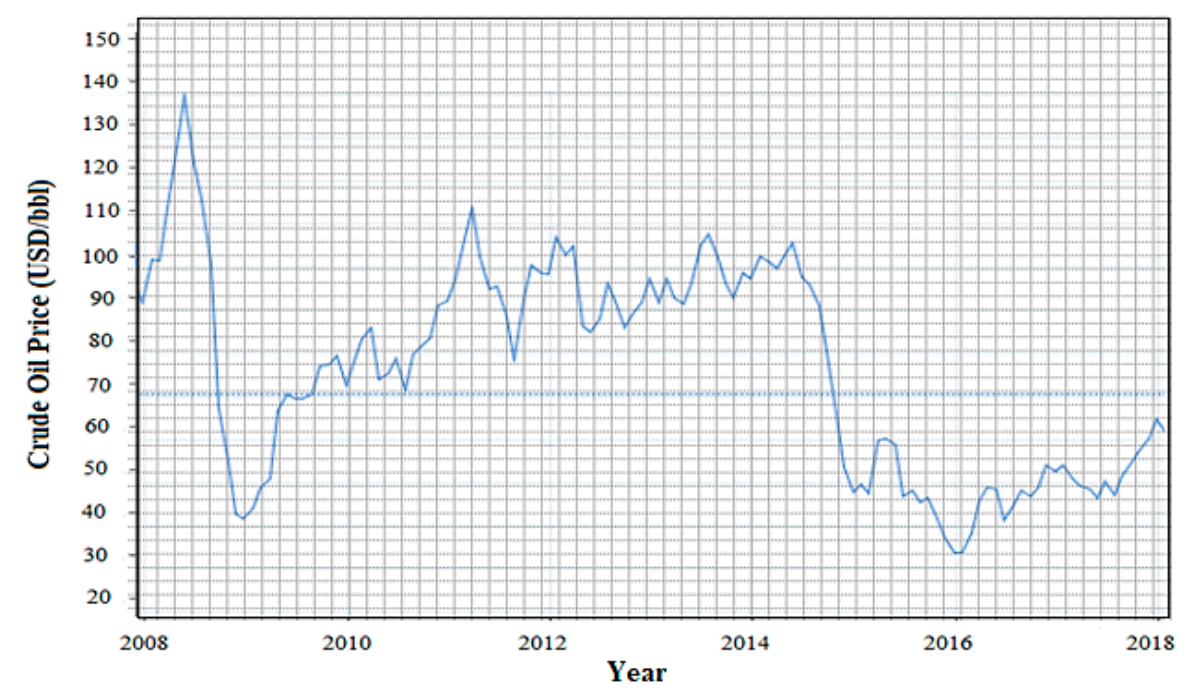

Figure 1. Annual crude oil price.

Table 3. Historical annual data for crude oil prices.

\begin{tabular}{ccccc}
\hline Year & Open Price & Low Price & High Price & Close Price \\
\hline 2008 & 99.64 & 30.28 & 145.31 & 44.60 \\
2009 & 46.17 & 34.03 & 81.03 & 79.39 \\
2010 & 81.52 & 64.78 & 91.48 & 91.38 \\
2011 & 91.59 & 75.40 & 113.39 & 98.83 \\
2012 & 102.96 & 77.72 & 109.39 & 91.83 \\
2013 & 93.14 & 86.65 & 110.62 & 98.17 \\
2014 & 95.14 & 53.45 & 107.95 & 53.45 \\
2015 & 52.72 & 34.73 & 61.43 & 37.04 \\
2016 & 36.76 & 26.21 & 54.06 & 53.72 \\
2017 & 52.33 & 42.53 & 60.42 & 60.42 \\
2018 & 60.37 & 42.53 & 76.41 & 45.41 \\
\hline
\end{tabular}


The method employed in this investigation is based on the method of Nandha and Brooks (Nandha and Brooks 2009). Subsequently, all of the models originate from CAPM (Sharpe 1964; Lintner 1965; Black 1972; Jensen et al. 1972). Considering Soytas and Oran (Soytas and Oran 2011), Ghosh (Ghosh 2011), Narayan and Sharma (Narayan and Sharma 2011), all of the models are GARCH and include the heteroskedasticity features of the returns time series (Lamoureux and Lastrapes 1990).

Stock-market price forecasting is considered as one of the most challenging operations of financial time series prediction. The complexity of predicting originates from the attributes of non-linear and non-stationary of stock market trends and financial time series. The novel model proposed by (Sedighi et al. 2019a, 2019b) could be employed to accurately predict the stock's future prices of oil companies.

The outcomes attained by applying non-stationary time series may be spurious since they may show a nexus between two variables in which one does not exist. Before achieving the point of conversion for the non-stationary financial time series data, the different types of non-stationary processes should be determined. It results in a better comprehension of the procedures and lets implement the appropriate and acceptable modification. In an effort to achieve compatible and dependable results, the non-stationary data are required to be converted into stationary data.

Previously, Box-Jenkins methods, for instance the autoregressive and ARIMA methods, were presented to deal with this challenge (Chatfield 2000). Even so, these methods were designed based on the supposition that the time series being predicted are linear and stationary. Recently, nonlinear methods have been introduced, including ARCH, GARCH, ANN, FNN and SVR. Hence, the aforementioned issues are the main reasons for employing GARCH model in this investigation (Nelson 1991; Bollerslev et al. 1994; Hansen and Nelson 1997; Tay and Cao 2001; Kim 2003).

The Model 1 is a classic model of CAPM in which changes in crude oil prices are added as variables, according to Equations (2)-(6). This model examines whether AR has a significant influence on oil company stock yields and what kind of nexus exists between these factors. Taking into consideration that there is a nexus between the stock exchange and crude oil (Park and Ratti 2008; Narayan and Narayan 2010; Soytas and Oran 2011; Cunado and de Gracia 2014; Narayan and Gupta 2015), to characterize the market impact, a market element is utilized which is not described by the oil price index.

$$
\begin{gathered}
R_{i t}=\alpha_{i}+\beta_{i} \times R_{W, t}^{o}+\gamma_{i} \times R_{O, t}+e_{i t} \\
T_{i t}^{2}=\varphi_{0}+\varphi_{1} e_{i, t}^{2}+\varphi_{2} T_{i, t}^{2} \\
e_{i t}=T_{i t} \vartheta_{t} ; \vartheta_{t} \sim N(0,1) \\
R_{W, t}-\left(b_{0}+b_{1} \times R_{O, t}\right) \\
R_{W, t}=a+\gamma+R_{O, t}+u_{t}
\end{gathered}
$$

The second model (Equations (7)-(9)) aims to evaluate whether negative market fluctuations and oil price variations after AR have a significant effect on oil stock returns and consequently if the asymmetry is available in regards to the positive alterations.

$$
\begin{gathered}
R_{i t}=\alpha_{i}+\beta_{i} \times R_{W, t}^{o}+\beta_{i}^{A} \times\left(R_{W, t}^{o} \times A_{M}\right)+\gamma_{i} \times R_{O, t}+\gamma_{i}^{A} \times\left(R_{O, t} \times A_{o}\right)+e_{i t} \\
T_{i t}^{2}=\varphi_{0}+\varphi_{1} e_{i, t-1}^{2}+\varphi_{2} T_{i, t-1}^{2} \\
e_{i t}=T_{i t} \vartheta_{t} ; \vartheta_{t} \sim N(0,1)
\end{gathered}
$$

The third model (Equations (10)-(12)) aims to determine whether market alternations and crude oil prices after AR with a lag of 1 period have a significant impact on oil stock yields and the type of 
nexus existing amid these factors. Compared to the first model, it can be specified if a lag exists in decision making by the traders regarding the changes in crude oil prices.

$$
\begin{gathered}
R_{i t}=\alpha_{i}+\beta_{i} \times R_{W, t}^{o}+\gamma_{i} \times R_{O, t-1}+e_{i t} \\
T_{i t}^{2}=\varphi_{0}+\varphi_{1} e_{i, t-1}^{2}+\varphi_{2} T_{i, t-1}^{2} \\
e_{i t}=T_{i t} \vartheta_{t} ; \vartheta_{t} \sim N(0,1)
\end{gathered}
$$

Finally, the fourth model (Equations (13)-(15)) is a broader model used to analyze whether crude oil price shocks have a significant influence on stock returns of petroleum companies. This model is based on the hypothesis that there is an overreaction in the oil stock price while the crude oil price alterations are excessive and unusual.

$$
\begin{gathered}
R_{i t}=\alpha_{i}+\beta_{i} \times R_{W, t}^{o}+\gamma_{i} \times R_{O, t}+\gamma_{i}^{A} \times\left(R_{O, t} \times A_{o}\right)+e_{i t} \\
T_{i t}^{2}=\varphi_{0}+\varphi_{1} e_{i, t-1}^{2}+\varphi_{2} T_{i, t-1}^{2} \\
e_{i t}=T_{i t} \vartheta_{t} ; \vartheta_{t} \sim N(0,1)
\end{gathered}
$$

\section{Results and Discussion}

In implementing the first model, the outcomes indicate that the market has a significant and positive impact on most petroleum companies with regard to the oil price, the AR and conceivable opportunities. With regard to the condition observed, the market typically affects most oil companies if the price after removal of asphaltenes is taken into account compared to the previous price, especially for monthly and annual assessments. For $71 \%$ of the stocks of petroleum companies, the $\beta_{i}$ is lower than 1 , which shows a negative impact of the market return in the conventional CAPM model. A total of $29 \%$ of the petroleum companies examined have a $\beta_{i}$ more than 1 and therefore have an increasing influence on the market (See Table 4).

Table 4. The outcomes of Model 1.

\begin{tabular}{ccc|ccc}
\hline Stock Symbol & $\beta_{i}$ & $\gamma_{i}$ & Stock Symbol & $\beta_{i}$ & $\gamma_{i}$ \\
\hline XOM & 0.3475 & 0.0827 & SWN & 0.4215 & 0.1288 \\
EGY & 0.5442 & 0.0682 & HES & 1.4776 & 0.1763 \\
WLL & 0.3425 & 0.2241 & RRC & 0.3537 & 0.1495 \\
WPX & 0.6874 & 0.2143 & LNGG & 0.4125 & 0.1357 \\
REXX & 0.1456 & 0.1796 & PXD & 0.4308 & 0.0245 \\
NBL & 0.4796 & 0.0225 & MUR & 0.2677 & 0.0482 \\
LPI & 0.1488 & 0.2174 & NFX & 0.1263 & 0.0735 \\
OXY & 0.5306 & -0.0325 & CXO & 0.1245 & 0.1150 \\
COP & 0.1442 & 0.0942 & OAS & 0.1496 & -0.0463 \\
CLR & 1.3835 & 0.1586 & MRO & 1.2570 & -0.0285 \\
DNR & 0.1440 & 0.0236 & SD & 0.1442 & -0.1864 \\
DVN & 0.3207 & 0.8525 & SM & 1.2205 & -0.1433 \\
EGN & 1.4335 & -0.1174 & CHK & 0.4176 & 0.0775 \\
EOG & 0.7508 & -0.2366 & CVX & 0.2635 & 0.0424 \\
EQT & 0.2445 & 0.0835 & XEC & 0.3309 & 0.0655 \\
\hline
\end{tabular}

In terms of returns, daily price changes have a greater impact on stocks of petroleum companies. It is worth noting that the removal of asphaltenes is the most positive effect of daily frequency, suggesting that an increase in the oil prices enhances the value of petroleum companies. By contrast, in the monthly and annual range, most of the revenue is decreased given the increment of one of the major costs of petroleum companies. 
A total of $58 \%$ of oil companies influence the stock price before/after the asphaltene. For the WTI analysis, 77\% have monthly and annual market impact, showing a significant impact of the market on stock prices of petroleum companies.

In the daily evaluation (See Table 5), $61 \%$ of the petroleum companies have an interest in the market and oil coefficients. The outcome is appealing because it demonstrates a share of the oil price oscillations to the stock return in a significant percentage of the petroleum companies surveyed.

Table 5. Significance of market and petroleum effects based on first model.

\begin{tabular}{cccccccc}
\hline & & \multicolumn{3}{c}{ Market } & \multicolumn{3}{c}{ Petroleum } \\
\cline { 3 - 7 } & & $\mathbf{S}^{\mathbf{3}}$ & $\mathbf{P}^{\mathbf{4}}$ & $\mathbf{N}^{\mathbf{5}}$ & $\mathbf{S}$ & $\mathbf{P}$ & $\mathbf{N}$ \\
\hline \multirow{3}{*}{ PPBAR $^{1}$} & Daily & $81 \%$ & $81 \%$ & $0 \%$ & $67 \%$ & $38 \%$ & $14 \%$ \\
& Monthly & $68 \%$ & $68 \%$ & $0 \%$ & $31 \%$ & $20 \%$ & $14 \%$ \\
& Yearly & $83 \%$ & $83 \%$ & $0 \%$ & $41 \%$ & $27 \%$ & $16 \%$ \\
\hline \multirow{2}{*}{ PPAAR $^{2}$} & Daily & $85 \%$ & $85 \%$ & $0 \%$ & $44 \%$ & $28 \%$ & $14 \%$ \\
& Monthly & $56 \%$ & $56 \%$ & $0 \%$ & $33 \%$ & $15 \%$ & $12 \%$ \\
& Yearly & $90 \%$ & $90 \%$ & $0 \%$ & $51 \%$ & $46 \%$ & $13 \%$ \\
\hline
\end{tabular}

${ }^{1}$ Petroleum Price before Asphaltene Removal; ${ }^{2}$ Petroleum hypothetical Price after Asphaltene Removal; ${ }^{3}$ Significant;

${ }^{4}$ Positive; ${ }^{5}$ Negative. The level of significant coefficients: $5 \%$.

For $32 \%$ of the petroleum companies' stocks investigated, the WTI price fluctuations are significant in the daily and monthly evaluation (at the 5\% level), and in $68 \%$ of these instances, the signal of the impact is preserved, demonstrating the stability of the impacts. After integration of the symmetry-related artificial variables into the second model (Tables 6 and 7), the number of substantial oil and market coefficients diminishes as compared to the first model.

In the daily models, the market importance diminishes, whereas the returns diminish even more. Regarding asymmetry, more than $29 \%$ of the petroleum companies indicate this impact compared to the market, meaning that negative changes in comparison with positive fluctuations have a greater effect on stocks price changes of petroleum companies.

However, the oil price asymmetry impact on stock prices is not considered greater than $75 \%$ of the cases. In addition, the most instances of the oil impact are positive in the daily evaluation.

Table 6. The outcomes of Model 2.

\begin{tabular}{ccccc|ccccc}
\hline $\begin{array}{c}\text { Stock } \\
\text { Symbol }\end{array}$ & $\boldsymbol{\beta}_{\boldsymbol{i}}$ & $\boldsymbol{\beta}_{\boldsymbol{i}}^{\boldsymbol{A}}$ & $\boldsymbol{\gamma}_{\boldsymbol{i}}$ & $\boldsymbol{\gamma}_{\boldsymbol{i}}^{\boldsymbol{A}}$ & $\begin{array}{c}\text { Stock } \\
\text { Symbol }\end{array}$ & $\boldsymbol{\beta}_{\boldsymbol{i}}$ & $\boldsymbol{\beta}_{\boldsymbol{i}}^{\boldsymbol{A}}$ & $\gamma_{\boldsymbol{i}}$ & $\boldsymbol{\gamma}_{\boldsymbol{i}}^{\boldsymbol{A}}$ \\
\hline XOM & 0.4153 & 0.0425 & 0.1274 & 0.0747 & SWN & 0.2746 & 0.0125 & 0.0807 & 0.1278 \\
EGY & 0.2965 & 0.1374 & 0.0530 & 0.1510 & HES & 1.8323 & 0.4510 & 0.2872 & 0.0742 \\
WLL & 0.1457 & 0.2298 & 0.1341 & 0.0745 & RRC & 0.3541 & 0.5186 & 0.0721 & 0.1153 \\
WPX & 0.4235 & 0.3104 & 0.1752 & 0.0879 & LNGG & 0.2365 & 0.2372 & 0.6530 & 0.4122 \\
REXX & 0.3146 & 0.4035 & 0.0329 & 0.0535 & PXD & 0.2980 & 0.3863 & 0.1707 & 0.6273 \\
NBL & 0.1205 & 0.0318 & 0.1840 & 0.2146 & MUR & 0.2605 & 0.3029 & 0.1556 & 0.1396 \\
LPI & 0.6301 & 0.2436 & 0.8782 & 0.3533 & NFX & 0.0198 & 0.2553 & 0.5741 & 0.1865 \\
OXY & 0.6402 & 0.0596 & 0.4675 & 0.0855 & CXO & 0.0574 & 0.3641 & 0.9125 & 0.2340 \\
COP & 0.2908 & 0.3573 & 0.4727 & 0.5443 & OAS & 0.3435 & 0.0920 & 0.3307 & 0.4875 \\
CLR & 1.1680 & 0.1654 & 0.1223 & 0.5298 & MRO & 1.5014 & 0.2909 & 0.0469 & 0.0755 \\
DNR & 0.8603 & 0.8318 & 0.0598 & 0.7163 & SD & 0.9325 & 1.6351 & 0.6123 & 0.1868 \\
DVN & 0.7215 & 0.1940 & 0.1563 & 0.2305 & SM & 1.4002 & 0.1795 & 0.1585 & 0.0354 \\
EGN & 1.8002 & 0.2336 & 0.4854 & 0.2774 & CHK & 0.4183 & 0.4336 & 0.8966 & 0.1525 \\
EOG & 1.1305 & 0.3294 & 0.0585 & 0.8236 & CVX & 0.3505 & 0.2465 & 0.7105 & 0.4633 \\
EQT & 0.1417 & 0.2473 & 0.1763 & 0.0509 & XEC & 0.5821 & 0.1271 & 0.0132 & 0.1376 \\
\hline
\end{tabular}


Table 7. Significance of market and petroleum effects based on second model.

\begin{tabular}{cccccccccc}
\hline & & \multicolumn{2}{c}{ Market } & \multicolumn{2}{c}{ Market Artificial } & \multicolumn{2}{c}{ Petroleum } & \multicolumn{2}{c}{ Petroleum Artificial } \\
\cline { 3 - 9 } & & $\mathbf{S}$ & $\mathbf{P}$ & $\mathbf{S}$ & $\mathbf{P}$ & $\mathbf{S}$ & $\mathbf{P}$ & $\mathbf{S}$ & $\mathbf{P}$ \\
\hline \multirow{3}{*}{ PPBAR } & Daily & $57 \%$ & $57 \%$ & $35 \%$ & $16 \%$ & $21 \%$ & $7 \%$ & $11 \%$ & $14 \%$ \\
& Monthly & $31 \%$ & $31 \%$ & $17 \%$ & $6 \%$ & $14 \%$ & $5 \%$ & $12 \%$ & $4 \%$ \\
& Yearly & $23 \%$ & $23 \%$ & $19 \%$ & $6 \%$ & $10 \%$ & $4 \%$ & $13 \%$ & $4 \%$ \\
\hline \multirow{3}{*}{ PPAAR } & Daily & $59 \%$ & $59 \%$ & $38 \%$ & $19 \%$ & $13 \%$ & $7 \%$ & $14 \%$ & $15 \%$ \\
& Monthly & $33 \%$ & $33 \%$ & $14 \%$ & $13 \%$ & $18 \%$ & $8 \%$ & $10 \%$ & $2 \%$ \\
& Yearly & $26 \%$ & $26 \%$ & $11 \%$ & $8 \%$ & $14 \%$ & $3 \%$ & $10 \%$ & $2 \%$ \\
\hline
\end{tabular}

A total of $41 \%$ of the petroleum companies have a substantial positive market influence and the WTI asymmetry consequences, showing that virtually one-third of the petroleum companies stocks are influenced by WTI price tendencies. It is challenging to examine that all situations of asymmetry are positive, which means that when the WTI price diminishes the effect is greater than if the price of WTI rises. This consequence is displayed for any daily reports.

For the implementation of the third model, which incorporates different market variables and lagged oil prices, Tables 8 and 9 were obtained.

Table 8. The outcomes of Model 3.

\begin{tabular}{ccc|ccc}
\hline Stock Symbol & $\beta_{i}$ & $\gamma_{i}$ & Stock Symbol & $\beta_{i}$ & $\gamma_{i}$ \\
\hline XOM & 0.3910 & 0.0821 & SWN & 0.3391 & 0.0451 \\
EGY & 0.4435 & 0.0485 & HES & 1.4205 & 0.0212 \\
WLL & 0.2706 & 0.2612 & RRC & 0.4322 & 0.0271 \\
WPX & 0.8251 & 0.2114 & LNGG & 0.3705 & 0.1405 \\
REXX & 0.6103 & 0.1423 & PXD & 0.3242 & 0.0351 \\
NBL & 0.0705 & 0.0031 & MUR & 0.2374 & 0.0059 \\
LPI & 0.5812 & 0.1415 & NFX & 0.1563 & 0.0301 \\
OXY & 0.5781 & 0.0372 & CXO & 0.1788 & 0.0672 \\
COP & 0.1379 & 0.0561 & OAS & 0.0095 & -0.1585 \\
CLR & 1.4005 & 0.0088 & MRO & 1.2802 & -0.0207 \\
DNR & 0.1377 & 0.0214 & SD & 0.0923 & -0.0512 \\
DVN & 0.5804 & 0.1235 & SM & 1.5689 & -0.0603 \\
EGN & 1.3418 & -0.0784 & CHK & 0.5203 & 0.0889 \\
EOG & 0.8805 & -0.0503 & CVX & 0.3241 & 0.0202 \\
EQT & 0.0470 & 0.0297 & XEC & 0.3517 & 0.0795 \\
\hline
\end{tabular}

Table 9. Significance of market and petroleum effects based on third model.

\begin{tabular}{cccccccc}
\hline & & \multicolumn{3}{c}{ Market } & \multicolumn{3}{c}{ Petroleum } \\
\cline { 3 - 7 } & & $\mathbf{S}$ & $\mathbf{P}$ & $\mathbf{N}$ & $\mathbf{S}$ & $\mathbf{P}$ & $\mathbf{N}$ \\
\hline \multirow{3}{*}{ PPBAR } & Daily & $88 \%$ & $88 \%$ & $0 \%$ & $45 \%$ & $36 \%$ & $6 \%$ \\
& Monthly & $75 \%$ & $75 \%$ & $0 \%$ & $32 \%$ & $19 \%$ & $3 \%$ \\
& Yearly & $72 \%$ & $72 \%$ & $0 \%$ & $46 \%$ & $35 \%$ & $14 \%$ \\
\hline \multirow{3}{*}{ PPAAR } & Daily & $88 \%$ & $88 \%$ & $2 \%$ & $51 \%$ & $37 \%$ & $11 \%$ \\
& Monthly & $62 \%$ & $62 \%$ & $0 \%$ & $19 \%$ & $12 \%$ & $7 \%$ \\
& Yearly & $73 \%$ & $73 \%$ & $0 \%$ & $38 \%$ & $32 \%$ & $12 \%$ \\
\hline
\end{tabular}

The substantial rates from the market preserve likeness with those of the model with the variables of the first model. In most situations, the market has more effect in comparison with the first model, indicating the impact of the market on the stock return of petroleum companies.

The market impact is perfectly positive for all the conditions. After checking the market coefficient in the daily examines, we found that in $66 \%$ of the cases which have a significant market impact, the 
oil impact is indicated to supplement the market impact. That is why the $\beta_{\mathrm{i}}$ enhances in $49 \%$ of the petroleum companies' stocks.

A total of $68 \%$ of assessed stocks of petroleum companies have a significant market impact in the daily evaluation, which represents $77 \%$ of the petroleum companies that have a lagged oil impact. $51 \%$ of the petroleum companies have two impacts, and in $79 \%$ of these situations, the two impacts are positive, verifying the efficient-market hypothesis. In the several situations with a positive market impact and a negative WTI impact, the market coefficient $\left(\beta_{i}\right)$ is higher than 1 , accordingly, the WTI impact has a compensatory influence. Eventually, while evaluating the fourth model, which contains the shock impacts of intense changes in oil prices, the impact on the market is broadly the same as for the main model.

The considerable changes in oil prices decrease with a higher percentage in the monthly and also annual models; however, in the daily surveys, the oil is comparatively equivalent to the first model. In monthly and annual surveys, it is certainly not easy to determine whether the impact is positive or negative because the result is not apparent. In the monthly evaluation, $89 \%$ and $91 \%$ positive market impact on the petroleum companies' stock return is noteworthy, which represents an extensive expository strength. The outcomes are accessible in Tables 10 and 11.

Table 10. The outcomes of Model 4.

\begin{tabular}{cccc|cccc}
\hline $\begin{array}{c}\text { Stock } \\
\text { Symbol }\end{array}$ & $\beta_{i}$ & $\gamma_{i}$ & $\gamma_{i}^{A}$ & $\begin{array}{c}\text { Stock } \\
\text { Symbol }\end{array}$ & $\beta_{i}$ & $\gamma_{i}$ & $\gamma_{i}^{A}$ \\
\hline XOM & 0.3672 & 0.0808 & 0.0089 & SWN & 0.3285 & 0.0311 & 0.0193 \\
EGY & 0.4525 & 0.0705 & 0.0271 & HES & 1.6011 & 0.2446 & 0.0072 \\
WLL & 0.2214 & 0.1226 & 0.0415 & RRC & 0.3587 & 0.0862 & 0.2204 \\
WPX & 0.8351 & 0.1512 & 0.0200 & LNGG & 0.3401 & 0.0551 & 0.0797 \\
REXX & 0.5302 & 0.0572 & 0.0588 & PXD & 0.3305 & 0.0068 & 0.0726 \\
NBL & 0.0588 & 0.0075 & 0.0271 & MUR & 0.2438 & 0.0288 & 0.0401 \\
LPI & 0.6105 & 0.0798 & 0.0814 & NFX & 0.1302 & 0.0982 & 0.0253 \\
OXY & 0.6347 & 0.0057 & 0.1105 & CXO & 0.1489 & 0.0902 & 0.0221 \\
COP & 0.1223 & 0.0871 & 0.0187 & OAS & 0.0452 & 0.0471 & 0.0312 \\
CLR & 1.3102 & 0.1686 & 0.0862 & MRO & 1.3123 & 0.0204 & 0.0805 \\
DNR & 0.1514 & 0.0204 & 0.0063 & SD & 0.1625 & 0.1688 & 0.0301 \\
DVN & 0.5813 & 0.1811 & 0.0802 & SM & 1.5810 & 0.1317 & 0.0798 \\
EGN & 1.4205 & 0.0875 & 0.0721 & CHK & 0.4568 & 0.0886 & 0.0412 \\
EOG & 0.8500 & 0.2140 & 0.0214 & CVX & 0.3891 & 0.1112 & 0.0672 \\
EQT & 0.0514 & 0.0411 & 0.0301 & XEC & 0.3468 & 0.0712 & 0.0310 \\
\hline
\end{tabular}

Table 11. Significance of market and petroleum effects based on fourth model.

\begin{tabular}{ccccccccccc}
\hline & & \multicolumn{3}{c}{ Market } & \multicolumn{3}{c}{ Petroleum } & \multicolumn{3}{c}{ Petroleum Artificial } \\
\cline { 3 - 10 } & & $\mathbf{S}$ & $\mathbf{P}$ & $\mathbf{N}$ & $\mathbf{S}$ & $\mathbf{P}$ & $\mathbf{N}$ & $\mathbf{S}$ & $\mathbf{P}$ & $\mathbf{N}$ \\
\hline \multirow{3}{*}{ PPBAR } & Daily & $85 \%$ & $85 \%$ & $0 \%$ & $48 \%$ & $33 \%$ & $13 \%$ & $11 \%$ & $7 \%$ & $4 \%$ \\
& Monthly & $72 \%$ & $72 \%$ & $0 \%$ & $10 \%$ & $2 \%$ & $9 \%$ & $14 \%$ & $11 \%$ & $4 \%$ \\
& Yearly & $70 \%$ & $70 \%$ & $0 \%$ & $10 \%$ & $2 \%$ & $9 \%$ & $14 \%$ & $11 \%$ & $4 \%$ \\
\hline \multirow{3}{*}{ PPAAR } & Daily & $88 \%$ & $88 \%$ & $0 \%$ & $48 \%$ & $33 \%$ & $13 \%$ & $11 \%$ & $7 \%$ & $4 \%$ \\
& Monthly & $68 \%$ & $68 \%$ & $0 \%$ & $10 \%$ & $2 \%$ & $9 \%$ & $11 \%$ & $9 \%$ & $3 \%$ \\
& Yearly & $65 \%$ & $65 \%$ & $0 \%$ & $10 \%$ & $2 \%$ & $9 \%$ & $11 \%$ & $9 \%$ & $3 \%$ \\
\hline
\end{tabular}

In the daily evaluation, nearly all cases have a severe impact and price change impact that go far beyond normal oil price fluctuations. In the majority of instances of severe impacts, the coefficient is unlike the oil price coefficient, suggesting an inverse effect for the instances of severe changes. Universally for all models, the petroleum companies' stocks have a market impact showing a tendency to coordinate with the market, and the identical impact can be obtained about the oil price fluctuations. These findings are remarkable and tangible because the market impacts are typical impacts to describe 
stock returns. The oil price oscillations include a description of what is left inexplicable by the market return, demonstrating the significance of oil price change tendencies in petroleum companies' stock returns. In most cases, the oil impact is positive and reinforces the efficient-market hypothesis.

\section{Conclusions and Investment Policy}

The commodity of crude oil is certainly the world's most vital energy source. Hence the oil price performs a significant role in industrial and economic improvement and it can affect financial markets, especially the stock exchange. This study has attempted to examine the effect of crude oil price variations after the AR on stock yields of petroleum companies listed on U.S. stock exchanges, utilizing Daily/Monthly/Yearly information overlaying the years from 2008 to 2018.

Asphaltene and its striking problems are serious concerns in the oil industry. It generates losses in productivity and rises in operational costs. The high viscosity of heavy oil causes a rise in recovery and transportation costs.

In the daily levels, the upgrading of heavy oil with the method of the AR has a positive impact on about $31 \%$ of the petroleum companies, and this figure for the monthly levels is close to $47 \%$. The annual results are remarkable: around $69 \%$ of petroleum companies are affected by oil price fluctuations after heavy oil upgrading. Asphaltene is a known trouble that happens during production operations in the petroleum industry and generates a substantial cost.

By our outcomes, we mentioned that when oil price variations after the AR had a direct positive impact on stock yields of the companies an indirect nexus also existed between oil price fluctuations after the AR and stock yields, and it was transferred via the market yields. Nevertheless, the indirect effect of oil price fluctuations after the AR on company's yields was greater than its direct impact. We also mentioned the existence of an indirect impact of oil yields and company's stock yields via the stock exchange. The outcomes obtained recommend that fluctuations in the oil price after the AR enhance stock yields.

These outcomes are momentous for traders in the stock market and futures exchange and commodity markets. In this investigation, we found that changes in crude oil prices following AR influence the stock yields of petroleum companies. This influence is fundamentally positive.

The information obtained confirmed the prospect of AR: When applied, the asset prices boost along with the market paradigm that boosts the petroleum price are indications of financial advancement and will improve the financial markets.

Considering these outcomes, an investment strategy should be applied to remove asphaltenes from petroleum. These outcomes also suggest that it is essential to evaluate the impacts of the AR in various sectors of the petroleum industry. These discoveries support the AR and authenticate the paradigm which is an indication of economic and financial growth in financial markets, especially stock exchange.

Crude oil price fluctuations have significant impacts on the financial statements of oil companies. Especially, companies with higher financial leverage deal with price risks more widely. Oil companies, oil traders and dealers hedge their activities with energy derivatives which employ financial contract tools that originate their value from the base commodity, particularly crude oil. Given this, the current study proposes the new investment policies in the petroleum industry to increase the revenue and decrease the costs and improve the financial statements of petroleum companies. These investment policies are summarized as follows:

- Invest in modern design systems and methods to remove asphaltene from crude oil.

- Invest in manufacturing and purchase of new devices to reduce the costs of the AR process.

- Invest in new approaches to control and manage the time of the AR process given the production levels and demand for oil to arrive at the best import-export balance by boosting oil reserves and production.

- Applying structured financing methods in oil-related project finance including heavy oil upgrading. 
- Industrial and commercial banks and similar financial institutions can operate as the issuer of securities for oil project loans that admitted to exchanging on an official market. These types of banks or institutions could analyze the different methods of project financing. In this process, insurance companies could rank these projects by the risk evaluation and finally, cover all-risk during all steps of oil-related projects.

- Insurance companies could manage the project finance risk by credit insurance. The credit insurance is being implemented in three kinds: (1) trade credit insurance, (2) payment protection insurance, (3) credit derivative.

- The government could issue special bonds to the petroleum companies. This type of bond is an innovative form which is transferable and would not affect the liquidity condition in the market. The bond market provides opportunities for corporations to secure money to finance projects or investments

- Securitization can perform a key task in oil projects finance via economical and low-cost financing through the financial markets.

These strategies can generate opportunities for the progress and development of oil companies and provide profitable approaches for traders and investors who focus on investment activities in the financial markets for their portfolio construction, hedging and risk management and, ultimately, international investing in crude oil swaps or oil futures contracts on the commodities and futures market. The development of these markets should be accompanied by the improvement of the market infrastructure. The obtained theoretical progress can be the basis literature for future research and some of the issues raised in this investigation can be explored profoundly.

Author Contributions: M.S. (Mojtaba Sedighi), Writing-Original Draft Preparation, Writing—Review \& Editing, Methodology, Formal Analysis; M.M., Investigation, Data Curation; S.F.F., Conceptualization, Resources; M.S. (Mehdi Sedighi), Validation, Supervision.

Funding: This research received no external funding.

Acknowledgments: The authors appreciate the Young Researchers and Elite Club affiliated to Islamic Azad University for their cooperation.

Conflicts of Interest: The authors declare no conflict of interest.

\section{Abbreviations}

The following abbreviations are used in this manuscript:

$\begin{array}{ll}\text { AR } & \text { Asphaltene Removal } \\ \text { PPBAR } & \text { Petroleum price before asphaltene removal } \\ \text { PPAAR } & \text { Petroleum hypothetical price after asphaltene removal } \\ \text { WTI } & \text { West Texas Intermediate } \\ \text { IEA } & \text { International Energy Agency } \\ \text { CAPM } & \text { Capital Asset Pricing Model } \\ \text { U.S. EIA } & \text { The United States Energy Information Administration } \\ \text { GARCH } & \text { Generalized Autoregressive Conditional Heteroskedasticity } \\ \text { ARDL } & \text { Autoregressive Distributed Lag } \\ \text { VAR } & \text { Vector Autoregressive } \\ \text { VECM } & \text { Vector Error Correction Models } \\ \text { ARCH } & \text { Autoregressive Conditional Heteroscedasticity } \\ \text { ARIMA } & \text { Autoregressive Integrated Moving Average } \\ \text { ANN } & \text { Artificial Neural Network } \\ \text { FNN } & \text { Fuzzy Neural Networks } \\ \text { SVR } & \text { Support Vector Regression }\end{array}$




\section{References}

Aloui, Chaker, Duc Khuong Nguyen, and Hassen Njeh. 2012. Assessing the impacts of oil price fluctuations on stock returns in emerging markets. Economic Modelling 29: 2686-95. [CrossRef]

Al-Tamimi, Hussein A. Hassan, Ali Abdulla Alwan, and A. Abdel Rahman. 2011. Factors affecting stock prices in the UAE financial markets. Journal of Transnational Management 16: 3-19. [CrossRef]

Arouri, Mohamed El Hedi, and Duc Khuong Nguyen. 2010. Oil prices, stock markets and portfolio investment: evidence from sector analysis in Europe over the last decade. Energy Policy 38: 4528-39. [CrossRef]

Arouri, Mohamed El Hedi, and Christophe Rault. 2012. Oil prices and stock markets in GCC countries: Empirical evidence from panel analysis. International Journal of Finance $\mathcal{E}$ Economics 17: 242-53.

Arouri, Mohamed El Hedi, Jamel Jouini, and Duc Khuong Nguyen. 2012. On the impacts of oil price fluctuations on European equity markets: Volatility spillover and hedging effectiveness. Energy Economics 34: 611-7. [CrossRef]

Black, Fischer. 1972. Capital market equilibrium with restricted borrowing. The Journal of Business 45: 444-55. [CrossRef]

Bollerslev, Tim. 1986. Generalized autoregressive conditional heteroskedasticity. Journal of Econometrics 31: 307-27. [CrossRef]

Bollerslev, Tim, Robert F. Engle, and Daniel B. Nelson. 1994. ARCH models. Handbook of Econometrics 4: 2959-3038.

Broadstock, David C., Hong Cao, and Dayong Zhang. 2012. Oil shocks and their impact on energy related stocks in China. Energy Economics 34: 1888-95. [CrossRef]

Çevik, Emrah, Erdal Atukeren, and Turhan Korkmaz. 2018. Oil Prices and Global Stock Markets: A Time-Varying Causality-In-Mean and Causality-in-Variance Analysis. Energies 11: 2848. [CrossRef]

Chatfield, Chris. 2000. Time-Series Forecasting. In Chapman and Hall/CRC. Boca Raton: CRC Press.

Chen, Nai-Fu, Richard Roll, and Stephen A. Ross. 1986. Economic forces and the stock market. Journal of Business 59: 383-403. [CrossRef]

Chen, Chaogang, Jixiang Guo, Na An, Yangqiu Pan, Yaguang Li, and Qingzhe Jiang. 2012. Study of asphaltene dispersion and removal for high-asphaltene oil wells. Petroleum Science 9: 551-7. [CrossRef]

Cheung, Yin-Wong, and Lilian K. Ng. 1996. A causality-in-variance test and its application to financial market prices. Journal of Econometrics 72: 33-48. [CrossRef]

Cong, Rong-Gang, Yi-Ming Wei, Jian-Lin Jiao, and Ying Fan. 2008. Relationships between oil price shocks and stock market: An empirical analysis from China. Energy Policy 36: 3544-53. [CrossRef]

Crude Oil Prices. 2008-2018. Available online: https://www.macrotrends.net/ (accessed on 1 May 2019).

Cunado, Juncal, and Fernando Perez de Gracia. 2014. Oil price shocks and stock market returns: Evidence for some European countries. Energy Economics 42: 365-77. [CrossRef]

DWAX. 2018. D-Wax Oilfield Solutions Ltd. Paraffin and Asphaltene Removal. Available online: https://dwax.ca/ (accessed on 1 May 2019).

El-Sharif, Idris, Dick Brown, Bruce Burton, Bill Nixon, and Alex Russell. 2005. Evidence on the nature and extent of the relationship between oil prices and equity values in the UK. Energy Economics 27: 819-30. [CrossRef]

Elyasiani, Elyas, Iqbal Mansur, and Babatunde Odusami. 2011. Oil price shocks and industry stock returns. Energy Economics 33: 966-74. [CrossRef]

Faff, Robert W., and Timothy J. Brailsford. 1999. Oil price risk and the Australian stock market. Journal of Energy Finance \& Development 4: 69-87.

French, Kenneth R., G. William Schwert, and Robert F. Stambaugh. 1987. Expected stock returns and volatility. Journal of Financial Economics 19: 3-29. [CrossRef]

Ghosh, Sajal. 2011. Examining crude oil price-Exchange rate nexus for India during the period of extreme oil price volatility. Applied Energy 88: 1886-9. [CrossRef]

Gogineni, Sridhar. 2010. Oil and the stock market: An industry level analysis. Financial Review 45: 995-1010. [CrossRef]

Halliburton. 2018. DuraKleen ${ }^{\circledR}$ Asphaltene Removal Service. Houston: Halliburton, Available online: http: //www.halliburton.com/ (accessed on 1 May 2019).

Hamilton, James D. 1983. Oil and the macroeconomy since World War II. Journal of Political Economy 91: 228-48. [CrossRef] 
Hamilton, James D. 1996. This is what happened to the oil price-macroeconomy relationship. Journal of Monetary Economics 38: 215-20. [CrossRef]

Hammoudeh, Shawkat, and Huimin Li. 2008. Sudden changes in volatility in emerging markets: The case of Gulf Arab stock markets. International Review of Financial Analysis 17: 47-63. [CrossRef]

Hansen, James V., and Ray D. Nelson. 1997. Neural networks and traditional time series methods: a synergistic combination in state economic forecasts. IEEE Transactions on Neural Networks 8: 863-73. [CrossRef] [PubMed]

Hong, Yongmiao. 2001. A test for volatility spillover with application to exchange rates. Journal of Econometrics 103: 183-224. [CrossRef]

Huang, Roger D., Ronald W. Masulis, and Hans R. Stoll. 1996. Energy shocks and financial markets. Journal of Futures Markets: Futures, Options, and Other Derivative Products 16: 1-27. [CrossRef]

IEA. 2018. International Energy Agency. Available online: www.iea.org (accessed on 1 May 2019).

Jensen, Michael C., Fischer Black, and Myron S. Scholes. 1972. The Capital Asset Pricing Model: Some Empirical Tests. Santa Barbara: Praeger Publishers Inc.

Jones, Charles M., and Gautam Kaul. 1996. Oil and the stock markets. The journal of Finance 51: 463-91. [CrossRef]

Jung, Hansol, and Cheolbeom Park. 2011. Stock market reaction to oil price shocks: A comparison between an oil-exporting economy and an oil-importing economy. Journal of Economic Theory and Econometrics 22: 1-29.

Kashefi, Sepideh, Abbas Shahrabadi, Mohammad Nader Lotfollahi, and Akbar Varamesh. 2016a. A new polymeric additive as asphaltene deposition inhibitor in $\mathrm{CO} 2$ core flooding. Korean Journal of Chemical Engineering 33: 3273-80. [CrossRef]

Kashefi, Sepideh, Abbas Shahrabadi, Shahin Jahangiri, Mohammad Nader Lotfollahi, and Hadi Bagherzadeh. 2016b. Investigation of the performance of several chemical additives on inhibition of asphaltene precipitation. Energy Sources, Part A: Recovery, Utilization, and Environmental Effects 38: 3647-52. [CrossRef]

Kilian, Lutz. 2009. Not all oil price shocks are alike: Disentangling demand and supply shocks in the crude oil market. American Economic Review 99: 1053-69. [CrossRef]

Kilian, Lutz, and Cheolbeom Park. 2009. The impact of oil price shocks on the US stock market. International Economic Review 50: 1267-87. [CrossRef]

Kim, Kyoung-Jae. 2003. Financial time series forecasting using support vector machines. Neurocomputing 55: 307-19. [CrossRef]

Kling, John L. 1985. Oil price shocks and stock market behavior. The Journal of Portfolio Management 12: 34-9. [CrossRef]

Lamoureux, Christopher G., and William D. Lastrapes. 1990. Heteroskedasticity in stock return data: Volume versus GARCH effects. The Journal of Finance 45: 221-9. [CrossRef]

Lee, Donggyu, and Jungho Baek. 2018. Stock Prices of Renewable Energy Firms: Are There Asymmetric Responses to Oil Price Changes? Economies 6: 59. [CrossRef]

Lee, Bi-Juan, Chin Wei Yang, and Bwo-Nung Huang. 2012. Oil price movements and stock markets revisited: A case of sector stock price indexes in the G-7 countries. Energy Economics 34: 1284-300. [CrossRef]

Lintner, John. 1965. Security prices, risk, and maximal gains from diversification. The Journal of Finance 20: 587-615.

Miller, J. Isaac, and Ronald A. Ratti. 2009. Crude oil and stock markets: Stability, instability, and bubbles. Energy Economics 31: 559-68. [CrossRef]

Mohammadi, M., E. Khamehchi, and M. Sedighi. 2014. The Prediction of Asphaltene Adsorption Isotherm Constants on Mineral Surfaces. Petroleum Science and Technology 32: 870-7. [CrossRef]

Mohammadi, Majid, Mehdi Sedighi, Hani Hashemi Kiasari, and Seyed MortezaTohidi Hosseini. 2015. Genetic Algorithm Development for Prediction of Modified Langmuir Isotherm Parameters of Asphaltene Adsorption onto Metal Surfaces: Using Novel Quartz Crystal Nanobalance. Journal of Dispersion Science and Technology 36: 384-92. [CrossRef]

Mohammadi, Majid, Mehdi Safari, Mostafa Ghasemi, Amin Daryasafar, and Mehdi Sedighi. 2019a. Asphaltene adsorption using green nanocomposites: Experimental study and adaptive neuro-fuzzy interference system modeling. Journal of Petroleum Science and Engineering 177: 1103-13. [CrossRef]

Mohammadi, Majid, Mehdi Sedighi, and Meysam Hemati. 2019b. Removal of petroleum asphaltenes by improved activity of $\mathrm{NiO}$ nanoparticles supported on green AlPO-5 zeolite: Process optimization and adsorption isotherm. Petroleum. in press. [CrossRef] 
Mohanty, Sunil K., Mohan Nandha, Abdullah Q. Turkistani, and Muhammed Y. Alaitani. 2011. Oil price movements and stock market returns: Evidence from Gulf Cooperation Council (GCC) countries. Global Finance Journal 22: 42-55. [CrossRef]

Nandha, Mohan, and Robert Brooks. 2009. Oil prices and transport sector returns: an international analysis. Review of Quantitative Finance and Accounting 33: 393. [CrossRef]

Nandha, Mohan, and Robert Faff. 2008. Does oil move equity prices? A global view. Energy Economics 30: 986-97. [CrossRef]

Narayan, Paresh Kumar, and Rangan Gupta. 2015. Has oil price predicted stock returns for over a century? Energy Economics 48: 18-23. [CrossRef]

Narayan, Paresh Kumar, and Seema Narayan. 2010. Modelling the impact of oil prices on Vietnam's stock prices. Applied Energy 87: 356-61. [CrossRef]

Narayan, Paresh Kumar, and Susan Sunila Sharma. 2011. New evidence on oil price and firm returns. Journal of Banking \& Finance 35: 3253-62.

Nelson, Daniel B. 1990. Stationarity and persistence in the GARCH $(1,1)$ model. Econometric Theory 6: 318-34. [CrossRef]

Nelson, Daniel B. 1991. Conditional heteroskedasticity in asset returns: A new approach. Econometrica: Journal of the Econometric Society, 347-70. [CrossRef]

Papapetrou, Evangelia. 2001. Oil price shocks, stock market, economic activity and employment in Greece. Energy Economics 23: 511-32. [CrossRef]

Para Solve Canada. 2018. Paraffin Wax Removal Solutions for Oil Well Servicing and Maintenance. Available online: https://parasolvecanada.ca/ (accessed on 1 May 2019).

Park, Jungwook, and Ronald A. Ratti. 2008. Oil price shocks and stock markets in the US and 13 European countries. Energy Economics 30: 2587-608. [CrossRef]

Sadorsky, Perry. 1999. Oil price shocks and stock market activity. Energy Economics 21: 449-69. [CrossRef]

Sadorsky, Perry. 2001. Risk factors in stock returns of Canadian oil and gas companies. Energy Economics 23: 17-28. [CrossRef]

Safari, Mehdi, Majid Mohammadi, and Mehdi Sedighi. 2017. Effect of neglecting geothermal gradient on calculated oil recovery. Journal of Applied Geophysics 138: 33-9. [CrossRef]

Sedighi, Mehdi, Majid Mohammadi, and Mojtaba Sedighi. 2018a. Green SAPO-5 supported NiO nanoparticles as a novel adsorbent for removal of petroleum asphaltenes: Financial assessment. Journal of Petroleum Science and Engineering 171: 1433-42. [CrossRef]

Sedighi, Mehdi, Majid Mohammadi, Mojtaba Sedighi, and Mostafa Ghasemi. 2018b. Biobased Cadaverine as a Green Template in the Synthesis of NiO/ZSM-5 Nanocomposites for Removal of Petroleum Asphaltenes: Financial Analysis, Isotherms, and Kinetics Study. Energy \& Fuels 32: 7412-22.

Sedighi, Mojtaba, Hossein Jahangirnia, and Mohsen Gharakhani. 2019a. A New Efficient Metaheuristic Model for Stock Portfolio Management and its Performance Evaluation by Risk-adjusted Methods. International Journal of Finance and Managerial Accounting 3: 63-77.

Sedighi, Mojtaba, Hossein Jahangirnia, Mohsen Gharakhani, and Saeed Farahani Fard. 2019b. A Novel Hybrid Model for Stock Price Forecasting Based on Metaheuristics and Support Vector Machine. Data 4: 75. [CrossRef]

Shaeri, Komeil, and Salih Katircioğlu. 2018. The nexus between oil prices and stock prices of oil, technology and transportation companies under multiple regime shifts. Economic Research-Ekonomska Istraživanja 31: 681-702. [CrossRef]

Sharpe, William F. 1964. Capital asset prices: A theory of market equilibrium under conditions of risk. The Journal of Finance 19: 425-42.

Soytas, Ugur, and Adil Oran. 2011. Volatility spillover from world oil spot markets to aggregate and electricity stock index returns in Turkey. Applied Energy 88: 354-60. [CrossRef]

Tay, Francis E.H., and Lijuan Cao. 2001. Application of support vector machines in financial time series forecasting. Omega 29: 309-17. [CrossRef]

Wei, Chao. 2003. Energy, the stock market, and the putty-clay investment model. American Economic Review 93: 311-23. [CrossRef] 
Yu, Lean, Shouyang Wang, and Kin Keung Lai. 2008. Forecasting crude oil price with an EMD-based neural network ensemble learning paradigm. Energy Economics 30: 2623-35. [CrossRef]

Zhu, Huiming, Xianfang Su, Yawei Guo, and Yinghua Ren. 2016. The Asymmetric Effects of Oil Price Shocks on the Chinese stock market: Evidence from a quantile impulse response perspective. Sustainability 8: 766. [CrossRef] 